\title{
Evolution of a new sense for wind in flying phasmids? Afferents and interneurons
}

\author{
Reinhold Hustert • Rebecca Klug
}

Received: 12 January 2009 /Revised: 28 July 2009 / Accepted: 28 July 2009 /Published online: 25 August 2009

(C) The Author(s) 2009. This article is published with open access at Springerlink.com

\begin{abstract}
The evolution of winged stick insects (phasmids) from secondarily wingless ancestors was proposed in recent studies. We explored the cuticle of flying phasmids for wind sensors that could be involved in their flight control, comparable to those known for locusts. Surprisingly, windsensitive hairs (wsH) occur on the palps of mouthparts and on the antennae of the winged phasmid Sipyloidea sipylus which can fly in tethered position only when air currents blow over the mouthparts. The present study describes the morphology and major functional properties of these "new" wsH with soft and bulging hair bases which are different from the beakerlike hair bases of the wsH on the cerci of phasmids and the wsH described in other insects. The most sensitive wsH of antennae and palps respond with phasic-tonic afferents to air currents exceeding $0.2 \mathrm{~ms}^{-1}$. The fields of $\mathrm{wsH}$ on one side of the animal respond mainly to ventral, lateral, and frontal wind on the ipsilateral side of the head. Afferent inputs from the wsH converge but also diverge to a group of specific interneurons at their branches in the suboesophageal ganglion and can send their integrated input from wsH fields of the palps and antennae to the thoracic central nervous system. Response types of individual wsH-interneurons are either phasic or phasic-tonic to air puffs or constant air currents and also, the receptive fields of individual interneurons differ. We conclude that the "new" wsH system and its interneurons mainly serve to maintain flight activity in airborne phasmids and also, the "new" wsH must have emerged together with the integrating interneurons during the evolution from wingless to the recent winged forms of phasmids.
\end{abstract}

\section{R. Hustert $(\triangle) \cdot$ R. Klug}

JFB-Institut für Zoologie und Anthropologie,

Georg-August-Universität Göttingen,

Berliner Str. 28, 37073 Göttingen, Germany

e-mail: rhuster@gwdg.de

R. Klug

e-mail: rklug@gwdg.de
Keywords Wind-sensitive hairs .

Winged phasmid evolution · Interneurons

\section{Introduction}

Winged stick insects may have re-evolved wings that emerged from basal phasmid lineages which had been wingless, according to a recent hypothesis (Whiting et al. 2003). Our question in this respect was whether the recent flying phasmids have also locations of specific wind-sensitive hairs (wsH) on their body that can control flight just as the wsH known from other flying orthopteran insects.

In locusts, specific wsH occur on the dorsal head capsule (Weis-Fogh 1956), the ventral prosternum (Pflüger and Tautz 1982), and the ovipositor (Kalogianni 1995) but not on mobile appendages (antennae, legs, and mouthparts), although such locations are known for many arachnids (review: Barth 2000). Another class of wsH exist on the cerci of most orthopteran insects and can cause various types of responses to air puffs to the rear and elicits even flight in locusts (Boyan et al. 1986). Phasmids respond to wind stimulation of their cercal wsH mainly with aversive shaking of the body, but they rarely elicit flight or contribute to the maintenance of flight in the winged phasmids as studied in Sipyloidea sipylus and Pseudophasma acanthonota (Grimm et al. 2007). Specific wsH could not be located on the head capsule or the prosternum of these or other winged phasmids, while behavioural tests with tethered animals demonstrated that their flight is initiated and maintained by focal air currents on the head (Grimm et al. 2007). Finally, the search for slender "filiform" sensory hairs that are deflected easily at their base by moderate air currents was successful: wsH exist on the palps of mouthparts and on the base of the antennae interspersed between smaller and thicker touch-sensitive 
mechanosensory hairs. They can be identified and stimulated reliably by application of moderate air puffs. With this experimental basis, we could start the present study to describe basic anatomical and physiological features of this "new" sensory system for air currents including the integration of its input in the central nervous system (CNS). In locusts, integrating interneurons that respond to wsH on the head capsule descend from the brain (Bacon and Tyrer 1978), and ascending interneurons from the abdominal CNS integrate input from the wsH on their prosternum (Pflüger and Tautz 1982).

From an evolutionary perspective, the specialised wsH of winged phasmids in peculiar locations on appendages of phasmids could have been either (1) retained from their winged ancestors, or (2) regained from their genetic pool during re-evolution of active flight in phasmids, or (3) evolved de novo to serve the newly established flight motor system.

Neural integration of afferent signals from the "new" wsH requires also a set of interneurons in the CNS which must have gained their specific integrative function along with the evolution of the wsH on appendages of the head in the winged phasmids. The evolution of such special interneurons may have occurred in different ways: (1) persistent interneurons altered their function from other tasks, (2) embryogenesis of interneurons changed to produce new interneurons parallel to the emerging wsH on palps and antennae, or (3) wsH-integrating interneurons were preserved genetically and re-evolved according to the neuronal wiring of an ancient pre-phasmid flight system. Indirect evidence for a long lasting maintenance of interneurons controlling the flight motor is given by the work on the wind-induced "pseudo-flight" activity obtained from thoracic muscles in recent wingless stick insects (Kutsch and Kittmann 1991). So, it is important for our study not only to describe the "new" afferent wsH system but also the "new" descending interneurons in the CNS which are specific for wsH input.

\section{Material and methods}

\section{Preparation}

Adult females of the parthenogenetic pink winged stick insect $S$. sipylus which is capable of flight were taken from our colony and chilled for anaesthesia to near $0^{\circ} \mathrm{C}$ before and during dissections. The legs were removed and the body fastened dorsal side down on a platform. The head was fixed while the antennae and mouthparts remained free to move. The soft cuticle of the ventral neck was removed for access to the suboesophageal ganglion (SOG), connectives, and peripheral nerves.
Stimulation

The very flexible wind hairs were identified as being the ones that move easily in their basal sockets when exposed to a focal air current or to local electrostatic fields (see also Birukow 1958) imposed by a small strip of plastic (polyvinyl chloride) that had been charged electrostatically by rubbing. These methods distinguished wsH from adjacent tactile hairs $(\mathrm{SH})$ on the palps and the antennae.

Controlled and focal stimulation of wsH on the palps or antennae was achieved by air blowing from a $100-\mathrm{ml}$ glass syringe (Kolbenprober, Fortuna) that was positioned vertically so gravity could move the piston smoothly downward and push air steadily out into a small diameter tubing system at a constant, aperture-dependent rate and at precise volumes. Start and stop of the current was controlled downstream by an electronic miniature valve (Lee, LFAA0509512H). The outlet nozzle $(2.3 \mathrm{~mm}$ in diameter) could be rotated precisely about the head for blowing a focal stream of air from a constant distance $(10 \mathrm{~mm})$ and at defined angles on either the mouthparts or the antenna of one side of the stick insect.

The velocity of air was recorded by a hot wire anemometer (electronics workshop of our institute) with its sensor located inside the tube, $15 \mathrm{~mm}$ from the outlet nozzle. Care was taken to neither impose nor elicit any movement of the antennae since in preliminary experiments that elicited massive discharges of descending interneurons which usually respond not to moderate air currents.

\section{Recording of neurons}

Suction electrodes, filled with saline, were used for extracellular recording of neural activity from afferent nerves and connectives. The same electrodes were used for recording from single wsH shafts that had been cut at half their length, exposing the internal lymph space. The cut end was brought into contact with the saline of the electrode tip for recording the antidromic action potentials arising from the wsH sensory cell (see also Camhi 1969). During that contact, the hair shafts could be stimulated mechanically by deflection in proximal, distal, and transversal directions relative to the axis of a palpus or antenna.

Intracellular recording from the SOG was performed after protease-softening of the ventral surface and penetration with glass electrodes of $60-80 \mathrm{M} \Omega$ tip resistance. The tips were filled with Lucifer yellow (in $1 \mathrm{M} \mathrm{LiCl}$ ). After recording from a neuron, the fluorescent stain was injected by standard methods into the neuron with hyperpolarizing currents of up to $5 \mathrm{~mA}$ to stain. The neuronal projections were visualised with an epi-fluorescence microscope and stored with a digital camera. 
Free flights of $S$. sipylus

Wing frequencies and flight speeds were extracted from free flights recorded against a background with a regular geometrical grid pattern using the high-speed video mode of a digital camera (Casio Exilim EX-F1) at 300 frames per second.
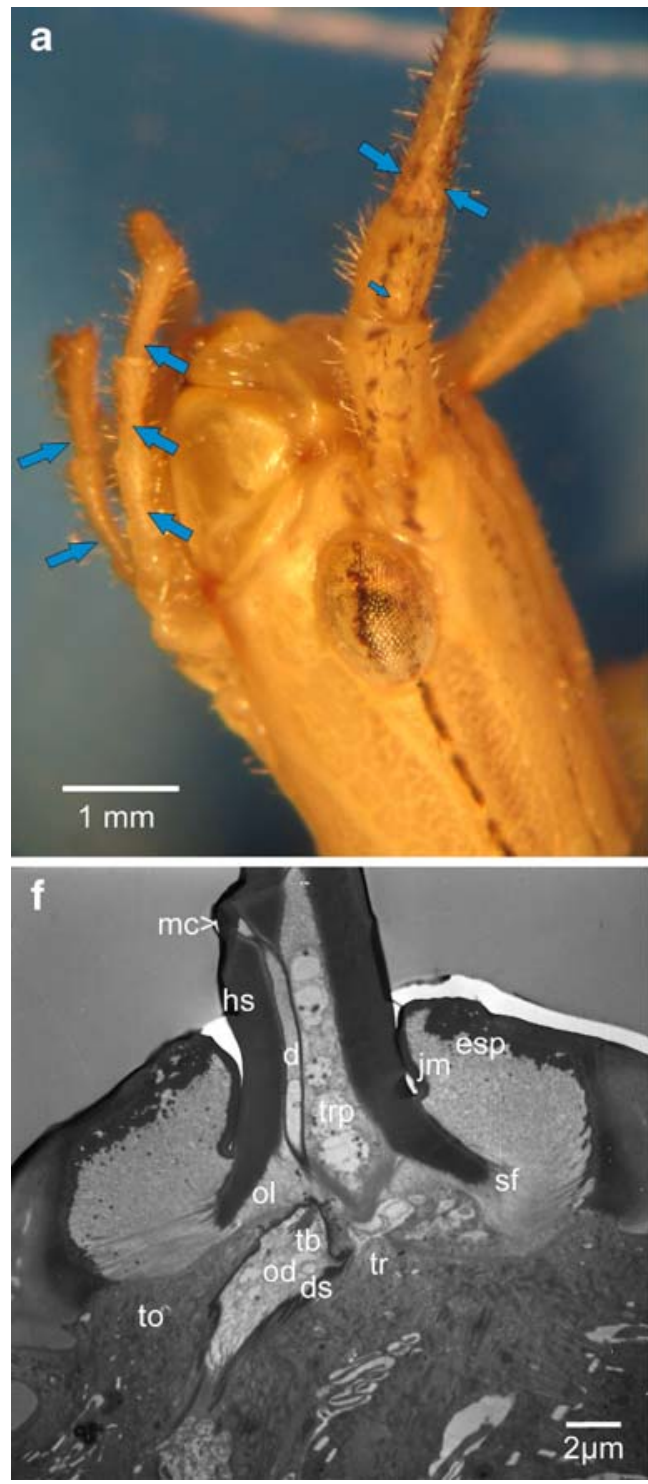

Fig. 1 Location and structure of wind-sensitive hairs (wsH) on the appendages on the head of the flying phasmid Sipyloidea sipylus. a Lateral view of the head with arrows indicating areas in which wsH (arrows) are located. b Part of the lateral surface of a labial palpus segment with several wsH (arrows) and their single sensory neurons stained with cobalt backfilling. c Ventral view of hairs on the labial palpus with arrows indicating identified wsH and directional sensitivity identified for one as antero-ventral $(a v)$. d Ventral view of hairs on the maxillar palpus with arrows indicating identified wsH and directional sensitivity identified for several as antero-ventral $(a v)$ and posteroventral $(p v)$. e Lateral view of the proximal flagellum $(f l 1)$ and pedicellus (ped) of the antenna with arrows to show wsH and two in which directional sensitivity was identified as antero-ventral $(a v)$ and

\section{Results}

Identification of $\mathrm{wsH}$ and basic function

wsH extend radial from the surface of the palps and the antennae of adult $S$. sipylus (Fig. 1) but also in earlier larval

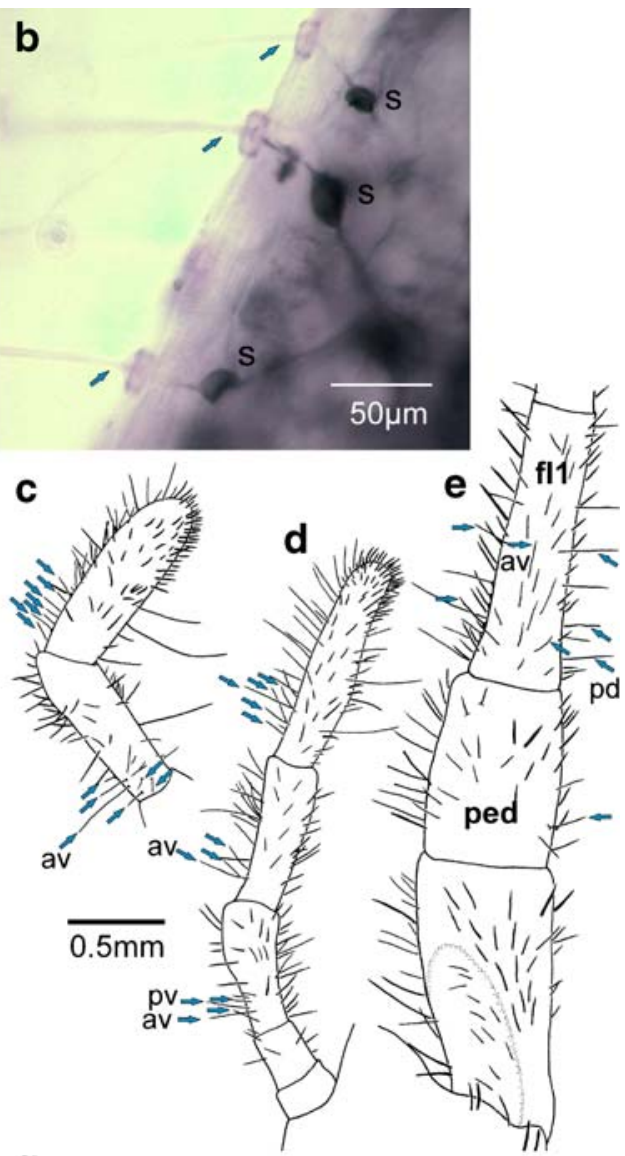

$\mathbf{g}$ antennal afferents

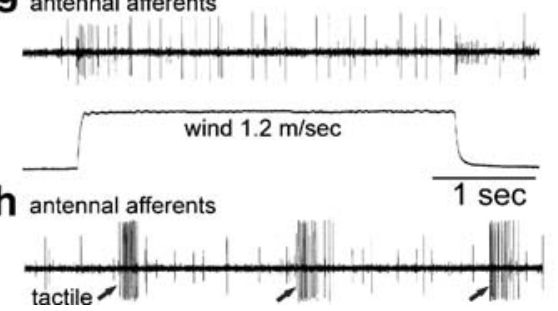

postero-dorsal $(p d)$. f Transmission electron microscopy of an antennal wsH base sectioned longitudinally through the hair shaft $(h s)$ at the level of the moulting canal $(m c)$ of the sensory dendrite $(d)$. That arises from the outer dendritic segment (od) with the tubular body $(t b)$ inside and surrounded by the dendritic sheath $(d s)$. The tormogen $(t o)$ and the trichogen cell ( $t r)$ lie adjacent, and a trichogen cell process (trp) extends into the hair shaft. The shaft is anchored in the outer lymph space $(o l)$ by suspension fibres $(s f)$ and surrounded by the joint membrane (jm) with underlying epicuticular spongiose material (esp) limiting hair deflections laterally. g Afferent nerve recording (upper trace) from an antennal nerve with the wsH stimulated by an air puff (wind recording below, $1.2 \mathrm{~ms}^{-1}$ ) lateral at the proximal flagellum. $\mathbf{h}$ The same antennal nerve recording as in $\mathbf{g}$. with tactile stimulation (arrows) of a single wsH 
stages. They look similar to most neighbouring tactile hairs in shape and colour except that they are generally more slender. The wsH can be identified only in living animals by wind stimulation or by the approach of an electrostatic field. Both stimulus types deflect their shafts in their socket from resting position, while all surrounding tactile hairs remain immobile. When palps and antennae were searched for wsH in wingless phasmids (Sungaya inexpectata and Ramulus thaii), none were found, whereas, only some single wsH were found in the short-winged, non-flying Haaniella dehaanii (both sexes stridulating for defence) and also in the short-winged females of Heteropteryx dilatata. In the excellent flyer $P$. acanthonota, larger groups of wsH were found just as in the moderate flyer S. sipylus.

The wsH have wide sockets (diameters from 15-25 $\mu \mathrm{m}$ ) in relation to the diameter of the hair shaft $(2-5 \mu \mathrm{m}$ near their base). The socket membrane bulges outward over the hard cuticular rim and allows lateral hair deflection for up to $20^{\circ}$. That stretches the membrane on one side and folds it on the other side of the shaft. On the palps, the wsH are $130-350 \mu \mathrm{m}$ long and in groups of three to ten wsH between other mechanosensitive hairs at the lateral circumference of each of the two maxillar and three labial distal segments (Fig. 1a). On the antennae, only one field of about ten wsH (length $150-350 \mu \mathrm{m}$ ) extends dorsally, laterally, and ventrally at the base of the first flagellar segment, and the pedicel carries just one single wsH in dorsal-lateral position. Recording from the antennal nerve shows phasictonic responses of single wsH both to moderate wind puffs and to selective touch (Fig. 1d).

The directional sensitivity to mechanical deflection of the wsH is observed best under moderate air flow (about $0.6 \mathrm{~ms}^{-1}$ ) applied at different angles of attack and perpendicular to the hair shaft. Typical wsH bending responses are oblique in respect to the long axis of their segment, that is, mainly proximal or mainly with a component of transverse bending in dorsal or ventral direction. Although wsH with proximal bending preference prevail, their direct neighbours can be responsive to opposite air currents. That was tested with mechanical displacement of neighbouring wsH while recording afferent responses from the tips of their cut shafts. All recorded wsH had a phasic-tonic afferent response characteristic that serves to record both increasing and constant air currents (Figs. 1d and 2). In contrast, all tactile hairs respond just phasic to touch and to wind puffs only that exceed velocities of $9 \mathrm{~ms}^{-1}$. In comparison, flight velocities of Sipyloidea range from about $0.1 \mathrm{~ms}^{-1}$ in hovering flight to $2.4 \mathrm{~ms}^{-1}$ at rapid descending flight. The longest wsH of palps are the most sensitive and move visibly in their elastic socket at wind speeds above $0.2 \mathrm{~ms}^{-1}$. At currents above $0.9 \mathrm{~ms}^{-1}$, their tips can bend while the shaft deflection halts near the rim of the socket. The shafts of the antennal wind hairs are generally thicker and stiffer, and their tips do not bend in moderate air currents.

When from a labial palpus nerve the compound afferent responses of wsH axons are recorded, their direction-dependent responses are strongest to lateral and frontal wind (Fig. 2). Recordings from palpus nerve afferents at wind speeds above $1.8 \mathrm{~ms}^{-1}$ that can move and bend the whole palpus may include responses from proprioceptive campaniform sensilla due to strain in the cuticle of the palpus segments. When Sipyloidea has taken its usual daytime position, hanging like a stick from the outstretched forelegs, the femora of their forelegs protect the palps from lateral wind.

Fine structure and innervation

All wsH shafts on the palps and antennae are hollow for at least half their length, but the trichogen cell from below the base maintains a process far up in their cavity. The wide base of the shaft always tapers within the socket to a slender shaft. From the basal rim of the shaft, strong tissue fibres connect radial to the surrounding hard cuticle of the socket (Fig. 1c). The diameter of the hard outer socket rim ranges from $14 \mu \mathrm{m}$ in the smallest wsH to $25 \mu \mathrm{m}$ in the largest wsH. From that protruding rim, the thin cuticular membrane of the socket bulges and forms an elastic "dome" which surrounds the hair shaft that arises from the middle of the socket. Around that shaft, the membrane bends downward fitting like a sleeve and finally connects to its base. The cuticle of the dome can stretch or fold in any direction when the hair shaft is deflected, but those movements are dampened by the thick internal layer of spongy material below the socket membrane (Fig. 1c).

Every wsH is supplied with one large sensory neuron (diameters 5-9 $\mu \mathrm{m}$ ) that inserts laterally with its dendrite inside the base of the hair shaft and terminates at the moulting canal (Fig. 1b, c). The tubular body inside the dendrite is located at the level of the wide circular rim of the shaft base. From that, cuticular rim extend neither specific indentation processes for the dendrite nor trunnions that could determine the direction of hair bending. The only specific structure attaching to the dendrite is the connective sheath of the process of the trichogen cell that extends into the lumen of the hair shaft. Afferent axon diameters of wsH sensory cells range from 0.8 to $2 \mu \mathrm{m}$, depending on the size of the whole wsH.

\section{Central afferent projections}

Primary afferent projections from wsH of the head reach the neuropile of the SOG in an ipsilateral medio-ventral region (Fig. 3), which is rich in tracts containing axons of many descending and ascending interneurons that can branch in this region of the ganglion also. Central projections from the 


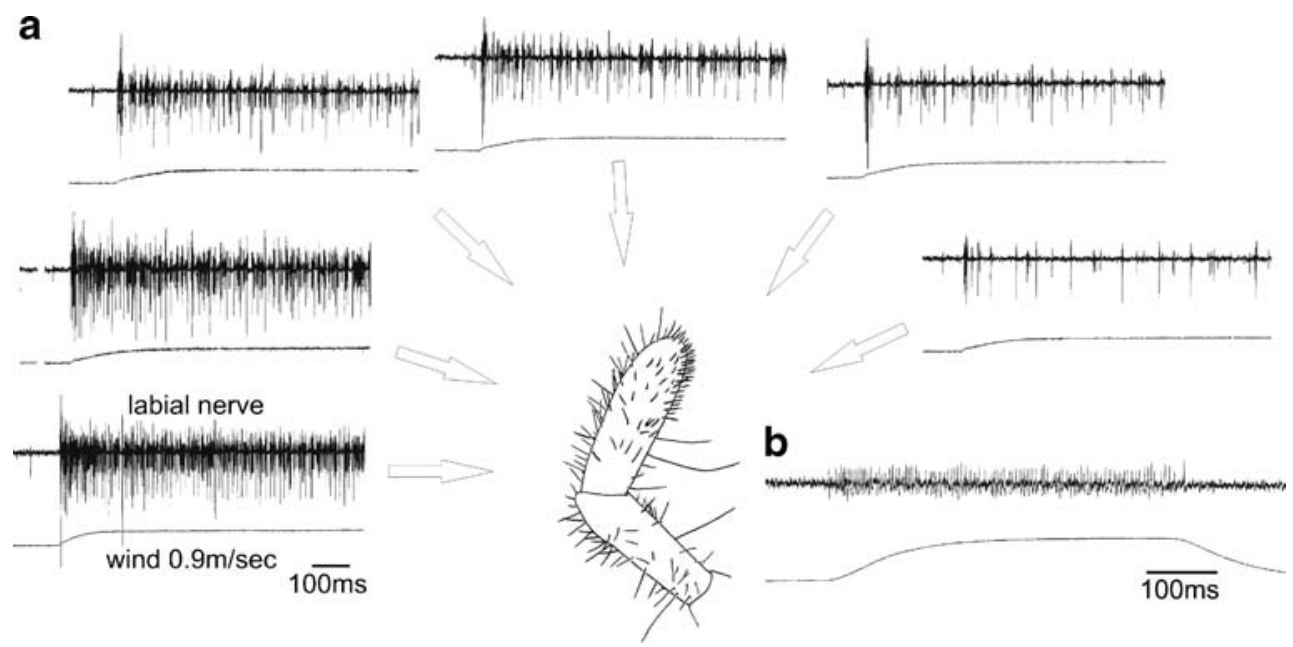

Fig. 2 Directional sensitivity of the wind-sensitive hairs (wsH) population of the labial palp. a Stimulation of the left labial palpus (middle, ventral view) with focal air currents of the same strength $\left(0.9 \mathrm{~ms}^{-1}\right.$, lower traces from anemometer) from different principal directions (arrows) while recording from the whole palpus nerve with a suction electrode (upper traces). b Microelectrode recording of a single palpus wsH afferent fibre from the neuropile of the suboesophageal ganglion with a phasic-tonic response at the onset of an air current $\left(1.2 \mathrm{~ms}^{-1}\right.$, lower trace $)$ applied laterally to the labial palpus a
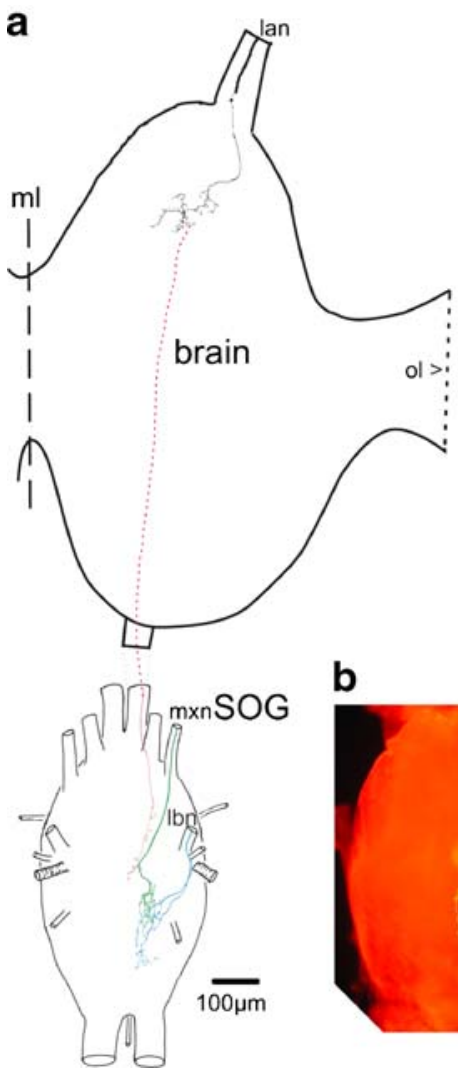

b

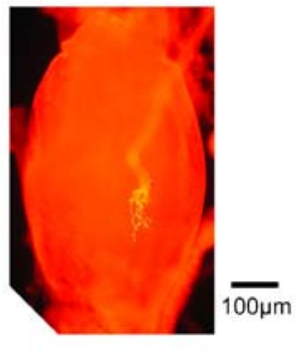

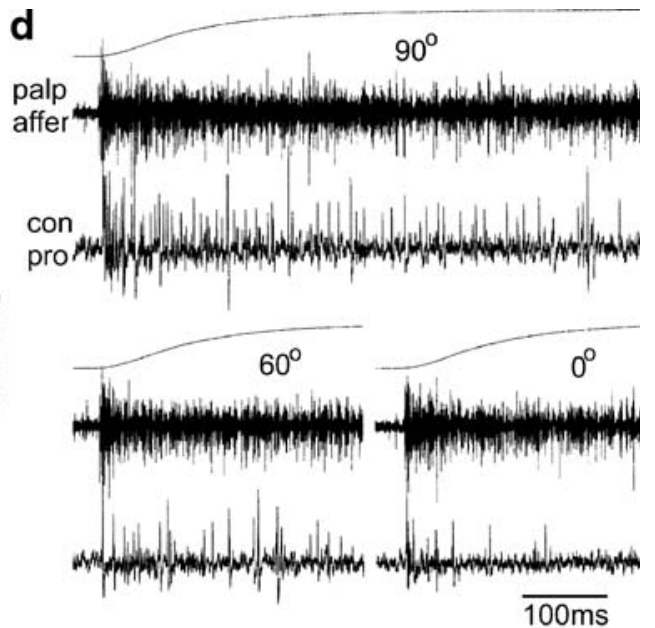

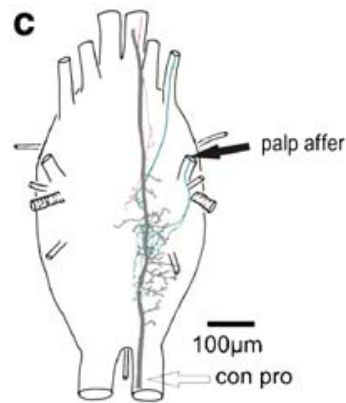

Fig. 3 Central projections of single wind-sensitive hairs (wsH) afferents in the central nervous system. a The antennal afferent enters the brain (right side; $\mathrm{ml}$ midline; ol optic lobe omitted; through the lateral antennal nerve (lan), branches in the antennal lobe descends in the connective and proceeds posterior to the suboesophageal ganglion (SOG). The wsH projections enter the SOG depending on their segmental origin through the anterior connective (red), the maxillary nerve (green, $m x n$ ), and the labial nerve (blue, lbn). b Original staining with dextrane/rhodamine of a maxillary wsH projection in the
SOG (ventral neuropile in focus). c Overlay of wsH projections (colours as in a) and one wsH-integrating interneuron (in grey, intracellular stain with Lucifer yellow) that descends from the brain to thoracic ganglia. d Simultaneous recording during focal wind stimulation (1.9 $\mathrm{ms}^{-1}$, upper traces) of the labial palpus from different directions (frontal $0^{\circ}$, oblique $60^{\circ}$, and lateral $90^{\circ}$ ) at a horizontal plane. The afferents (middle, palp affer) and resulting interneuron activity in descending connective (lower traces, con pro) were recorded as indicated by arrows in $\mathbf{c}$ 
maxillary palp wsH terminate medially and overlap in their posterior half of the ganglion with labial wsH projections. The intersegmental projections from the antennal wsH reach a comparable but more anterior region of the ganglion. The fine side-branches extend at a medio-ventral level of the neuropile. The initial afferent axon of the antennal wsH enters the brain via the antennal nerve and first branches extensively in the antennal lobe (anterior protrusion in phasmids) before the descending axon collateral enters the ipsilateral connective ventrally to proceed to the SOG.

\section{Interneuron responses to wsH}

The afferents from the wsH of palps and antennae cause spiking responses in at least four interneurons descending from the SOG through the posterior connectives (Figs. 3d and $4 d$, e). Usually two to three different units could be identified reliably by their relative spike amplitudes in extracellular recordings from the ventral surface of a connective when moderate wind below $1.5 \mathrm{~ms}^{-1}$ was blown onto the palps. When the air was focussed on the field of antennal wsH, two different types of interneurons responded regularly (Fig. 4d). Even the afferents from a single wsH alone (tactile stimulus) can diverge to at least two different descending windsensitive interneurons (Fig. 4d).

Response characteristics of individual interneurons can be strictly phasic (Fig. 4b, c), responding just to beginning or accelerating wind currents or phasic-tonic with responses also accelerating and constant wind current (Fig. 4a, e).

At least two of the interneurons we found receive input from all wsH fields ipsilateral and contralateral on the palps and antennae when these are stimulated selectively.

Intracellular recording revealed phasic-tonic responses to all wsH fields in one interneuron, whereas one large interneuron descending from the brain responded mainly phasic to wind onto the wsH of the contralateral antenna and of the ipsilateral palpus (and even multimodal to contralateral light changes). Since these features resemble that of the locust tritocerebral commissure giant (TCG) that traverses behind the brain between the descending connectives to SOG (Bacon and Möhl 1983), we looked for similarities in the CNS of Sipyloidea, but our backfilling of single connectives from the SOG into the brain with labelled dextranes revealed no descending interneurons that cross contralateral via the tritocerebral commissure. The backfill revealed only manifold crossing of descending neurons within the brain to the contralateral neuropiles.

In summary, responses of the wsH-interneurons were strongest to wind arriving ventrally on ipsilateral side of the animal, decreasing for more anterior wind and mostly weak to wind from the contralateral side.

Types of receptive fields of individual wsH-interneurons were determined experimentally by selective stimulation of wsH fields and with light. The results are listed in Table 1.

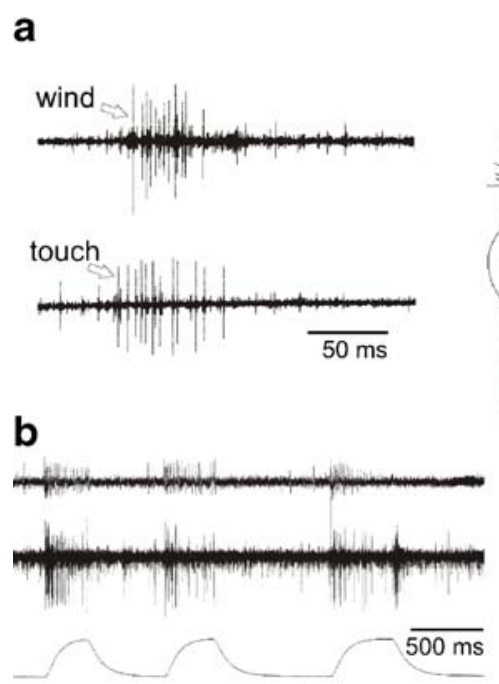

Fig. 4 Interneuron responses to selective wind stimulation. Inset: ventral view of the head with location of the suboesophageal ganglion and electrode positions for recording (left arrow: extracellular; right arrow: intracellular). a Responses of several wsH-interneurons with different spiking amplitudes to a wind puff (upper trace) and to tactile stimulation of a single palpus wsH recorded from the descending connective. b Phasic-tonic response of one interneuron recorded from the neuropile of the SOG (upper trace) and of several other interneurons recorded simultaneously from the descending connective (middle trace). Wind applied on ipsilateral palps, stimuli recorded
C

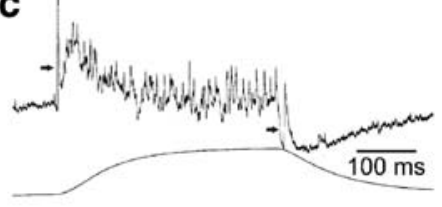

d

d $|H| \mid \quad$ antennal wsH interneuron

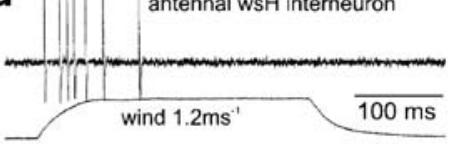

e

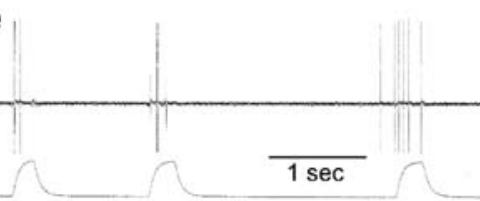

with an anemometer $\left(1.2 \mathrm{~ms}^{-1}\right.$, lower trace). c Phasic-tonic interneuron-response (upper trace) to a moderate wind stimulus $\left(0.6 \mathrm{~ms}^{-1}\right.$, lower trace) recorded from the posterior neuropile of the subesophageal ganglion. Arrows: artefacts of electric valve shutter for air stimuli. Wind applied on ipsilateral palps, recording below. d Phasic response of an interneuron connecting from the brain to the thoracic ganglia, recorded and stained from its axon in the SEG. Wind $\left(1.2 \mathrm{~ms}^{-1}\right)$ on ipsilateral antenna, recording below. e Axonal recording from a phasic wsH-interneuron during repetitive wind stimulation of the contralateral antenna $\left(1.2 \mathrm{~ms}^{-1}\right.$, lower trace $)$ 
Table 1 Receptive fields of different interneurons determined by selective wind stimulation of different locations of wind-sensitive hairs

\begin{tabular}{llllll}
\hline Interneuron & Antenna ipsi & Antenna contra & Palpus ipsi & Palpus contra & Visual \\
\hline TCG-like & - & + & - & - & + \\
Brain desc. & + & - & $(?)$ & + & - \\
SOG desc. & + & + & + & + & - \\
SOG desc. & + & - & + & + & - \\
SOG desc. & - & - & & + & - \\
\hline
\end{tabular}

\section{Discussion}

The study has shown that flying stick insects have evolved specific wsH that monitor flight-induced air currents on locations previously unknown for wind sensitivity: the palps of their mouthparts but also the base of their antennae. Their evolution must have been different from that of cercal wsH since the wsH on head appendages have a very specific morphology that is comparable in several aspects only to wind hairs on the head capsule of locusts (Smola 1970). Concurrently, a set of interneurons must have evolved for the specific function of integrating the afferents from the various fields of wsH on the palps and the antennae. It is unknown whether wsH were present on the head appendages of the ancestral flying species that preceded all present day lineages of flightless phasmids (Whiting et al. 2003) and winged phasmids. The wsH were first found on palps and antennae of S. sipylus and later only in other flying phasmid species that were available for comparison: the well flying males of Phyllium bioculatum, Extatosoma tiaratum, and $H$. dilatata (fewer wsH in the short-winged females) and the very good flier $P$. acanthonota. Presently, we have no clear answer to the new evolutionary question why the wsH of the antennae and palps occur just in the winged phasmids.

\section{Functional morphology of wsH}

A dominant morphological feature of the wsH is the wide and prominent socket from which a long and slender hair rises. The bulging socket membrane is similar to that of wsH on the locust head which also enwraps the shaft as a wide collar (Smola 1970). The collar dampens deflections and is supported in Sipyloidea by an internal layer of spongy but dense material composed of glomerular elements that seem to grow within the receptor lymph space. That reduces the sensitivity of the hairs to deflection adapting the system to air speed above $0.29 \mathrm{~ms}^{-1}$, a velocity the animal reaches immediately after takeoff for flight. In contrast, the cercal wsH of Sipyloidea (Klug and Hustert, unpublished) and crickets are more sensitive (Dumpert and Gnatzy 1977), since the socket membrane is very short and flexible and lies deep at the bottom of an open cuticular beaker (Gnatzy and Schmidt 1971). In crickets, also, a specific cuticular tooth can indent the sensory dendrite and at the base of the shaft trunnions articulate with the socket and thereby determine the specific swinging direction of each hair. Thus, the wsH of the phasmid antenna and palpus seem to be new evolutionary products, while on the same species, the common "Bauplan" for cercal wsH is expressed that is typical for many orthopteran groups (Keil 1997).

\section{WsH locations and wind measurement}

The sensory responses of phasmid head wsH to bending resemble that of locust wind hairs (Guthrie 1966), and their phasic-tonic response type is very suitable to record continuous air currents as encountered during flight.

Nevertheless, the location of flight controlling wsH on the palps of mouthparts of the winged phasmids contradicts our usual perception that palps of insect mouthparts are mainly appendages for search, probing, and uptake of food. The typical cuticular sensilla of insect palps are (1) contact chemosensory hairs, (2) mechanosensory hairs and bristles recording contacts, (3) proprioceptive hairplates near joints, and (4) also campaniform sensilla for recording cuticular strain caused by active or passive palp movements.

Functionally, it seems not very practical to have specialised wsH on palps or the antennae which are highly mobile appendages. Any movement of a palpus or antenna produces a different flow of air past each wsH which alters direction and strength of their shaft deflection and precludes reliable identification of wind directions by the primary afferents. On such a sensory basis, the nervous system can extract the feature "wind direction" only very roughly. For the wsH systems on the cerci, specifically of crickets (Edwards and Palka 1974), the direction of wind from lateral and from the rear can be resolved due to the relative immobility of the cerci and the sharp directional sensitivity of single hairs (similar observation in Sipyloidea: Böckmann and Hustert, unpublished data).

In summary, the angle between wind direction and body axis can only be analysed roughly by higher order neurons in the CNS from the population response of palpus $\mathrm{wsH}$ afferents (Fig. 2a) and from the comparison of left and right side wsH-interneuron activity. The prevailing function of 
the system is that of a driving input of the flight motor rather than steering any flight manoeuvres.

Why do the winged phasmids use two different systems to measure wind? The medium-sensitive and phasic-tonic wsH on the appendages perceive head on and lateral wind they encounter during flight, while the very sensitive and phasic cercal wsH can discriminate wind directions precisely in still or walking animals to elicit evasive or defensive reactions (Grimm et al. 2007). The cercal wsH also seem to be more sensitive to oscillations of air as produced by the approach of winged predators.

\section{Behavioural relevance}

Sipyloidea was observed to take off for flight from a substrate spontaneously, preferably at dawn, or by stimuli such as substrate vibrations and threatening visual signals (Grimm et al. 2007). Wind is rarely a cause for starting; it may rather inhibit flying in these "unskilled" fliers for there is danger of being entangled in surrounding shrubs. The wsH and integrating wsH-interneurons are wind-activated in still animals, but the tarsal contact can inhibit reflexinduced flight responses as was described for tarsal contact in many insects (Fraenkel 1932).

When Sipyloidea is airborne, a constant frontal wind can maintain the flight activity until the legs make contact again with a substrate. Apparently, the main functional significance of the wsH located on the antennal base and the palps is maintenance of flight since tethered animals stop flying when the wind on the head ceases (Grimm et al. 2007). For the sensory drive onto the flight motor in the CNS, the moderate wind sensitivity of $0.6 \mathrm{~ms}^{-1}$ or more seems sufficient for these wsH since the typical descending flights at a $25^{\circ}$ angle have velocities in the range of 0.1 to $2.4 \mathrm{~ms}^{-1}$ and use wing beat frequencies of $10-12 \mathrm{~Hz}$ (high-speed video-recordings of free flight).

Most wsH bend in oblique posterior directions by oncoming wind which is the most likely wind stimulus in the typical inclined flight position (between $40^{\circ}$ and $90^{\circ}$; Grimm et al. 2007) of Sipyloidea in free flight. Conversely, the anterior directional sensitivity of a smaller subpopulation of wsH might help sensing air that is moved by the own wing beats in normal flight (locusts: Bacon and Möhl 1983) or when the animal hovers and descends in flight with an almost vertical body position (Grimm et al. 2007).

\section{Afferent projections}

Projections from larger populations of afferents of palps were studied in locusts (Ignell et al. 2000), revealing suboesophageal projections and chemosensory collaterals through the circumoesophageal connective into the antennal lobe of the brain. Selectively stimulated projections from campaniform sensilla of the palps (Bräunig et al. 1983) remain local and ipsilateral just as we found for the wsH projections from the palps of Sipyloidea. These projections from antennal wsH of Sipyloidea also descend to the suboesophageal neuropile after their first branching in the antennal neuropile of the brain indicates divergence of their input to different interneurons. The antennal wsH projection show considerable differences to those from the head capsule of locusts (Tyrer et al. 1979). Although the projection areas of the wsH afferents from the different appendages of Sipyloidea overlap, they seem to branch most extensively in the neuropile associated with their segment of origin. That seems sufficient to connect to the wsH-integrating interneurons which descend in tracts of the SOG.

\section{Interneuron activity}

Only wsH-interneurons that extend to the flight motor centres in the thoracic ganglia can transfer information from the wsH located on the head. The thoracic central pattern generator for flight can be excited but also motoneurons involved in flight may be influenced directly. In locusts, sets of wind-specific interneurons descending from the head ganglia of insects have been identified, mainly the TCG and the tritocerebral commissure dwarf interneuron which respond to focal stimulation of wsH of their head capsule (Bacon and Tyrer 1978; Tyrer et al. 1988). For the second wsH system of locusts on the prosternum, another set of specific interneurons involved in steering flight was identified (Pflüger and Tautz 1982; Münch 2006). So, it is not a surprise that we were able to describe five specific interneurons for the completely different system of the flying phasmid Sipyloidea. They all have different integration properties, with responses more phasic for two interneurons and more phasic-tonic for the others. The extent of receptive fields is also different. The large phasic wsH-interneuron responds to contralateral antennal wsH and to light, which functionally resembles the TCG of locusts, although no interneuron descends in Sipyloidea from the brain to the SOG via the tritocerebral commissure. It is more or less a "novelty indicator", but it may also record wind turbulences elicited by wing beats as reported for the TCG of locusts (Bacon and Möhl 1983). The more continuous responses of the other wsH-interneurons of Sipyloidea to persistent wind should provide a steady neural drive to continue flight until other sensory input like tarsal contact becomes predominant.

The evolutionary emergence of specific integrating interneurons in cooperation with the wsH system of the head appendages remains obscure. One possibility is that they emerged from a group of interneurons that previously recorded any antennal movements by means of proprioceptors at the scapus-pedicellus joint which is supposed 
to influence flight steering in locusts and other insects (Gewecke 1975)

Acknowledgements Our thanks go to Silvia Gubert for excellent technical help with electron microscopy and sensilla staining and to Sven Bradler for discussions. This study was funded partly by the DFG (Wi599/13).

Open Access This article is distributed under the terms of the Creative Commons Attribution Noncommercial License which permits any noncommercial use, distribution, and reproduction in any medium, provided the original author(s) and source are credited.

\section{References}

Bacon J, Möhl B (1983) The tritocerebral commissure giant (TCG) wind-sensitive interneurone in the locust I. Its activity in straight flight. J Comp Physiol 150:439-452

Bacon J, Tyrer M (1978) The tritocerebral commissure giant (TCG): a bimodal interneurone in the locust, Schistocerca gregaria. J Comp Physiol 126:317-325

Barth FG (2000) How to catch the wind: spider hairs specialized for sensing the movement of air. Naturwissenschaften 87(2):51-58

Birukow G (1958) Zur Funktion von Antennen bei Mistkäfern (Geotrupes silvaticus Panz.). Z Tierpsychol 15/3:265-276

Boyan GS, Ashman S, Ball EE (1986) Initiation and modulation of flight by a single giant interneuron in the cercal system of the locust. Naturwissenschaften 73:272-274

Bräunig P, Pflüger H-J, Hustert R (1983) The specificity of central nervous projections of locust mechanoreceptors. J Comp Neurol 218(2):197-207

Camhi JM (1969) Locust wind receptors I. Transducer mechanisms and sensory response. J Exp Biol 50:335-348

Dumpert K, Gnatzy W (1977) Cricket combined mechanoreceptors and kicking response. J Comp Physiol 122:9-25

Edwards JS, Palka J (1974) The cerci and abdominal giant fibres of the house cricket Acheta domesticus. I Anatomy and physiology of normal adults. Proc R Soc Lond Ser B 185:83-103

Fraenkel G (1932) Untersuchungen über die Coordination von Reflexen und automatische-nervosen Rhythmen bei Insecten. I. Die Flugreflexe der Insecten und ihre Koordination. Z Vgl Physiol 16:371-393
Gewecke M (1975) The influence of the air-current sense organs on the flight behaviour of Locusta migratoria. J Comp Physiol 103:79-95

Gnatzy W, Schmidt K (1971) Die Feinstruktur der Sinneshaare auf den Cerci von Gryllus bimaculatus Deg. (Saltatoria, Gryllidae). I. Die Faden- und Keulenhaare. Z Zellforsch Mikrosk Anat 122:190-209

Grimm UJ, Klug R, Hustert R (2007) How winged phasmids start their flights. Species, Phylogeny \& Evolution 1(2):99-108

Guthrie DM (1966) The function and fine structure of the cephalic air flow receptor in Schistocerca gregaria. J Cell Sci 1:463470

Ignell R, Anton S, Hansson BS (2000) The maxillary palp sensory pathway of Orthoptera. Arthropod Struct Dev 29:295-305

Kalogianni E (1995) Physiological properties of wind-sensitive and tactile trichoid sensilla on the ovipositor and their role during oviposition in the locust. J Exp Biol 198:1359-1396

Keil TA (1997) Functional morphology of insect mechanoreceptors. Microsc Res Tech 39:506-531

Kutsch W, Kittmann R (1991) Flight motor pattern in flying and nonflying Phasmida. J Comp Physiol A 168:483-490

Münch D (2006) Untersuchungen von Strukturmerkmalen zur Aufklärung von NO-Wirkung, Wachstumsregulation und Verhaltenseigenschaften in Neuronennetzwerken von Locusta migratoria und Manduca sexta. Dissertation FU Berlin

Pflüger H-J, Tautz J (1982) Air movement sensitive hairs and interneurons in Locusta migratoria. J Comp Physiol 145:369380

Smola U (1970) Untersuchung zur Topographie, Mechanik und Strömungsmechanik der Sinneshaare auf dem Kopf der Wanderheuschrecke Locusta migratoria. Z Vgl Physiol 67:382-402

Tyrer NM, Bacon JB, Davies CA (1979) Sensory projections from the wind-sensitive head hairs of the locust Schistocerca gregaria. Distribution in the central nervous system. Cell Tissue Res 203: 79-92

Tyrer NM, Tyrer MF, Humbel U, Peters BH, Bacon JP (1988) The tritocerebral commissure 'dwarf' (TCD): a major GABAimmunoreactive descending interneurons in the locust. J Comp Physiol A 164:141-150

Weis-Fogh T (1956) Biology and physics of Locust flight IV. Notes on sensory mechanisms in locust flight. Philos Trans R Soc Lond B Biol Sci 239:553-584

Whiting MF, Bradler S, Maxwell T (2003) Loss and recovery of wings in stick insects. Nature 421:264-267 